\title{
Combining Project-Based Learning and Community-Based Research in a Research Methodology Course: The Lessons Learned
}

\author{
João Alberto Arantes do Amaral \\ Prof., Federal University of Sao Paulo, Brazil, jarantes@alum.mit.edu
}

\author{
Rebeca Júlia Rodrigues Lino dos Santos \\ Center of Systems Studies, Federal University of Sao Paulo, Brazil, \\ rebeca_julia@hotmail.com
}

In this article, we present our findings regarding the course "Research Methodology," offered to 22 first-year undergraduate students studying Administration at the Federal University of São Paulo, Osasco, Brazil. The course, which combined community-based research and project-based learning, was developed during the second semester of 2016. The students worked in teams to do research on a particular aspect of an NGO that helped people in need. The NGO was selected from a list of organizations that agreed to work as community partners. The students did qualitative research, which they then wrote up as a standard research paper for publication in a journal. Our research objective was to study the advantages and disadvantages of combining community-based research and project-based learning in research methodology courses. We followed a mixed-method research approach, analyzing the students' responses to a survey and focus group activities. Our main findings were as follows: 1) The students faced difficulties working in groups, scheduling meetings with the community partners, and creating the articles; 2) The project-based learning approach improved the students' learning; 3) Doing community-based research was rich and meaningful experience to the students; 4) The course was successful in developing the students' research skills.

Keywords: community-based research, research methodology, project-based learning, community-partners, systemic analysis

\section{INTRODUCTION}

In this article, we describe a Research Methodology course that involved communitybased research and followed a project-based learning approach. The course took place at the Federal University of São Paulo, Osasco Campus (Unifesp), during the second semester of 2016, with weekly lectures of four hours each. The course objective was to

Citation: Arantes do Amaral, J. A., \& Lino dos Santos, R. J. R. (2018). Combining Project-Based Learning and Community-Based Research in a Research Methodology Course: The Lessons Learned. International Journal of Instruction, 11(1), 47-60. https://doi.org/10.12973/iji.2018.1114a 
teach the 22 undergraduate students of Administration the steps in standard academic research. Students were also instructed in how to write up their research for publication in social science journals. The course was held in smart classroom; each student had a desktop with Internet connection and software office tools.

The first author decided to conduct the course following a project-based learning approach (PBL), challenging the students to work in teams to do research on a community partner NGO, and then to create an article together. Although students were given an overview of quantitative, qualitative and mixed methods research designs, the first author decided that the students would undertake qualitative research, using indepth interviews to collect data: each team would work on a pre-defined research question. We decided to follow this approach because the first-year students had not studied statistics previously, therefore it would have been very difficult to them to develop quantitative research. We developed questions that we thought would give the students an opportunity to undertake probing, in-depth interviews (see Table 1).

In order to gauge the students' response to the course, we followed a mixed method research approach, using surveys and focus group interviews. Our findings suggest that the project-based learning approach improved the students' learning and research skills despite the fact that the students encountered difficulties working in groups and writing the articles. We also found that the community-based research was rich and meaningful experience to the students, even though they faced difficulties in scheduling meetings with the community partners.

\section{BACKGROUND: THE RESEARCH METHODOLOGY COURSE}

Researchers (Ball \& Pelco, 2006) have stated that teaching research methods can be challenging because of the complexity of the issues and the tendency of students to lack interest in learning methodology. How can practitioners make a research methods course more interesting?

One possible way is by providing the students with a meaningful hands-on learning experience (McBurney, 1995; McConnell \& Marton, 2011), challenging them do research on real-life problems. In so doing the students can experience the entire process of the development of the research to the publication of the findings (Winn, 1995).

In order to provide our students with a meaningful experience, we decided to design a course where the students would learn research methodology by accomplishing real research, with clear research questions that would lead the students to interview people, analyze their answers, reach conclusions and to write articles about the experience.

But how could we do so, in a practical way?

Our answer to this question was to challenge the students to research the work conditions of our community partners, NGOs with whom we had worked with for many years in previous PBL courses. 
These NGOs develop very important social projects, helping people in need (victims of sexual abuse, homeless, elders abandoned by their families, children with serious diseases and so on). We considered that this kind of research would raise the students' interest in the course and research and would also help them to develop their sense of citizenship.

To lay the groundwork, before the course began, we contacted the NGOs. We explained the goals of the course, the kind of research that students would perform and asked them for their support, allowing the students to interview the key persons (directors, managers and people supported by the NGOs) of each institution.

We created a course website, with all information we thought would be useful to the students, including the course syllabus, the course schedule, the milestones and deliverables, the lecture notes (in video format), the readings, a list of relevant journals, in depth-interview guides and templates, links to NGO websites, and links to academic databases.

In the first class, we explained the course philosophy and objectives. We told the students that we were going to follow a project-based learning approach and explained its basic concepts. We also told them that they would work in teams of five to do the research and create an article. We explained that we had created pre-defined research questions related to the work of our community partners (the NGOs). Each team would visit the course website and choose the community partner and its corresponding research question (Table 1). We explained that in the following weeks, the students would do qualitative research, accomplishing in-depth interviews with representative from the community partners.

Table 1

The research objectives and the community partners, available in the course website

\begin{tabular}{ll}
\hline Research Objectives & Community partner \\
$\begin{array}{l}\text { Characterize the challenges of providing } \\
\text { help to homeless population. }\end{array}$ & $\begin{array}{l}\text { NGO "We Help." This NGO provides food to } \\
\text { the homeless population. }\end{array}$ \\
\hline $\begin{array}{l}\text { Characterize the challenges of providing } \\
\text { help to victims of sexual violence. }\end{array}$ & $\begin{array}{l}\text { NGO "Future Heirs." This NGO provides } \\
\text { psychological assistance to victims of sexual } \\
\text { violence. }\end{array}$ \\
\hline $\begin{array}{l}\text { Characterize the challenges of providing } \\
\text { educational opportunities to teenagers. }\end{array}$ & $\begin{array}{l}\text { NGO "Social Assistance Association." This } \\
\text { NGO provides free professional courses to } \\
\text { teenagers from poor neighborhoods. }\end{array}$ \\
\hline $\begin{array}{l}\text { Characterize the challenges of providing } \\
\text { support to orphanages. }\end{array}$ & $\begin{array}{l}\text { NGO "Institute Making History." This NGO } \\
\text { provides support to a network of orphanages. }\end{array}$ \\
\hline $\begin{array}{l}\text { Characterize the challenges of providing } \\
\text { support to people with visual impairment. }\end{array}$ & $\begin{array}{l}\text { NGO "Unit of Rehabilitation to People with } \\
\text { Visual Problems." This NGO provides } \\
\text { educational opportunities to people with visual } \\
\text { impairment. }\end{array}$ \\
\hline $\begin{array}{l}\text { Characterize the challenges of providing } \\
\text { support to children from poor families. }\end{array}$ & $\begin{array}{l}\text { NGO "Educational Spare Time." This NGO } \\
\text { provides nursery and educational support to } \\
\text { children from poor families. }\end{array}$ \\
\hline
\end{tabular}




\section{LITERATURE REVIEW}

In our course, we chose to follow a project-based learning approach (thereafter PBL), an approach that integrates theory with practice; the students are challenged to work in teams in order to develop a project, following an overall course schedule with welldefined milestones and deliverables (Markham, 2003; Bender, 2012). The students learn by doing, and research by themselves solutions to the problems they face (Gijselaers,1996). The professor acts more as consultant (Savery, 2006) by giving the students guidance about how to conduct their research and promoting opportunities for in-depth inquires and for knowledge sharing (Larmer \& Mergendoller, 2010). However, teaching a PBL course requires substantial planning on the part of the professor (Longmore, Dunn, \& Jarboe, 1996).

In our course, we challenge the students to do their research on institutions that help people in need. This kind of research, involving students, professors and community organizations, is called community-based research (Stoecker, 2003). Stocking and Cutforth (2006, p. 57) explain its benefits:

CBR provides students with opportunities to develop research products that further the work of community organizations that request this assistance. In addition, students gain skills in teamwork, problem-solving, and interpersonal relationships - skills that will serve them well in an increasingly complex society.

Researchers (Chapdelaine \& Chapman, 1999) point out that CBR can give the students the opportunity to learn research methodology in a practical way, by working closely with community partners.

Although there are several articles that describe the benefits of PBL and CBR, there is a lack of information about the advantages and disadvantages of combining both approaches. Our aim is to contribute to filling this gap by analyzing course in which both approaches were used.

\section{RESEARCH QUESTION}

Our research question then became: "What are the advantages and disadvantages of combining community-based research and project-based learning in research methodology courses?"

\section{METHOD}

\section{The course design and development}

The course was designed to follow a project-based learning approach. To ensure that students would have access to all information needed, we published a page on the course website with information about the project's activities, deliverables and the milestones (Figure 1). 


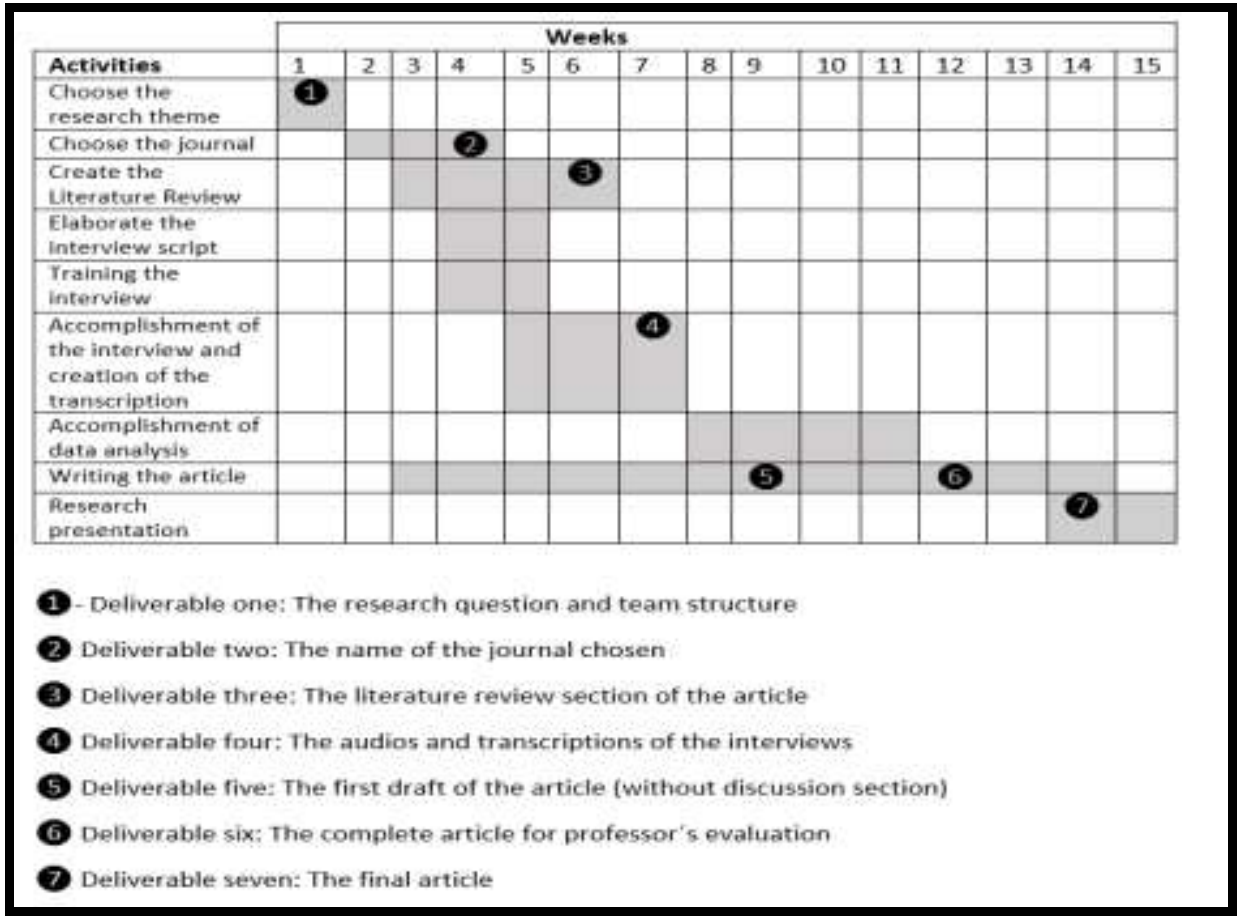

Figure 1

The planned activities, milestones and deliverables

By the end of the first class we asked the students to let us know which organization they had chosen and who would be on their team. We asked students to contact the community partners to schedule the interviews.

In the second class, we explained how social science research is conducted, talking about the difference between quantitative and qualitative research.

We talked to them about the importance of selecting the target journal at the beginning of the work. We explained what to take into account when selecting a journal. We showed them how to analyze a publication by looking at its scope, seeing what kind of articles it published, and identifying the journals' impact factors. We gave them practical examples of how to select a journal. We also alerted them about the existence of predatory journals.

In the third class, we gave an overview of the parts of a journal article: the abstract, the introduction, the methods, the results and the discussion. We explained how the parts fit together. After that we explained how to do a literature review. We described how to find academic articles by using academic databases such as Summon, ProQuest, Scielo and others. We also taught them how to reference sources with the text, showing them the different referencing styles (such as APA, MLA, Harvard and others). 
In the fourth class, we request that students present us the journal they had chosen, explaining what motivated their choice. After that, we explained them how to create indepth interviews. We described how to identify key informants and the concept of theoretical saturation. We oriented them as to how to conduct an interview. We also presented them with a model of an interview guide with probes that they could use in their interviews, making the necessary changes and adaptations.

In the fifth class, we discussed techniques of analyzing qualitative data. We gave detailed examples of how to compile, disassemble and reassemble data. We discussed how to identify the recurrent themes and how to interpret the results.

In the beginning of the sixth class each group presented the literature review section of their article. We evaluated each work and gave face-to-face feedback. Then we required them to revise their work and to return it to us the following week.

In the seventh class, we received the revised work and evaluated it again. While the work was better, corrections and modifications were needed. We asked students to do these for the following week. We also received transcripts and audios of the interviews. In this class, we taught the students how to create the discussion section of an article. We presented them with the concepts of systemic analysis, a means to connect the recurrent themes in a meaningful way.

In the eighth class, we gave examples of using systems thinking tools, such as causal loop diagrams and systemic maps, to connect the qualitative results, creating the discussion section of the article.

In the ninth class, we received the first draft of the articles. The articles did not have discussion sections yet. After receiving their work, we gave them practical exercises to create causal loop diagrams. The students worked on several short case studies, which allowed them to develop their skills in creating systemic maps.

In the tenth class, we discussed with each team the corrections that should be made in the articles. We spent the entire class clarifying issues and providing guidance.

In the eleventh class, we reviewed again what the sections of an academic article should contain. This time the students were much more interested; they had many questions. We analyzed, in detail, examples of peer-reviewed published articles. We discussed the peer-review process that academic journals usually follow.

In the twelfth class, the students delivered the final version of the article for our evaluation. We spent the entire class answering students' questions. We sent the students a survey, via-email, with questions about their perspectives on project-based learning and the classroom environment. They answered this email in class, using the smart room's computers.

In the first-half of the thirteenth class, we gave the students our feedback about the articles they had written and discussed with each team the corrections that should be made. In the second-half of the class we performed focus group interviews with each team. 
In the fourteenth class, the students handed in their final article and presented the results of their research to the class. In the final class, we wrapped up the course, discussing the lessons the professor and students had learned. We also discussed what the professor had learned by analyzing the students' answers to the survey.

\section{Research design}

We followed a mixed method research approach, using surveys and focus group interviews to gather data on students' responses to the course. We designed a survey that allowed us to collect quantitative data by means of closed-ended questions and qualitative data by means of open-ended questions. In addition, in order to obtain a better understanding of the students' answers and to figure out the causal relationships between the issues raised by them, we developed focus group interviews. We then analyzed the data by means of systemic maps.

\section{Participants}

All students enrolled for the course participated in this research. There were twenty-two first-year undergraduate students in Administration, aged from 19 to 22.

\section{Research instrument}

Our research instruments were the electronic survey (sent to each student by email) and the field notes (collected by the first author in focus group activities).

The survey had five close-ended questions (Appendix One) and ten open-ended questions (Appendix Two).

We designed three close-ended questions in order to ascertain whether the students had made use of the learning environment we created to support the course. We created questions about the utilization of the website, about the viewership of the video lectures and about the reading of the articles. We used a three-point Likert scale to collect their answers; basically we wanted to determine if they had made use of all the material, some of the material or none of it.

We also designed two close-ended questions in order to discover if the website facilitated the learning and if the students' involvement with a real institution also contributed their learning. We used a five point Likert scale in order to figure out how both actions had contributed to students' learning.

We designed the open-ended questions in order to understand the difficulties the students faced working in groups to create a research article. We wanted to understand their perspectives about the processes they followed in selecting a journal, accomplishing the interviews, researching academic journal databases, and creating specific sections of the article - the literature review, the discussion section, and so on. We also wanted to know what they considered as positive and negative aspects of the course. 


\section{Procedure of the research}

As described previously, the surveys were sent by email in the $12^{\text {th }}$ class. The focus group activity was developed in the $13^{\text {th }}$ class.

In the focus group activity, we interviewed each team and took field notes. We conducted the interviews in order to clarify issues raised by their answers to the survey. We challenged them to tell us about what had motivated them to work and what had discouraged them. We asked about the conflicts between the team members and about the rework they faced. We encouraged students to freely express their points of view.

\section{Data analysis}

We analyzed the quantitative data calculating the percentage $\left(100^{*}\right.$ number of students who answered the questions/total number of students and the qualitative data following the five-phased qualitative analysis method (Yin, 2015). Following this method, first we compiled the data from the students' answers to the qualitative questions and then grouped the data in closed-related clusters. After that we recombined the data into broader categories; we then interpreted the meaning of the groups and the interrelationships between them, and finally drew conclusions.

\section{FINDINGS}

\section{Findings from the survey}

The answers to the close-ended questions showed that eleven students visited the course's website several times, ten students visited a few times and one student never visited. The answers also revealed that one student watched all video-lectures, twenty watched some of videos and one student watched no videos. In addition, answers revealed that four students read all articles, fourteen read some of the articles and four read no articles.

In addition, sixteen students agreed with the statement "The course website facilitated my learning," three partially agreed and three were neutral about it.

Regarding the statement "Having a real institution to do my research on facilitated my learning," twelve students totally agreed, six partially agreed, one was neutral, one partially disagreed and two totally disagreed.

Four recurrent themes (RT) emerged from the analysis of the students' answers to the open-ended questions.

RT 1: The students faced difficulties working in groups, meeting with the community partners, and creating the articles.

The students told us that they faced three different types of difficulties. First, they had problems working in teams, primarily because some members were non-participative. Second, they had difficulties creating the articles, particularly with regard to the literature review section. Thirdly, the students acknowledged that some groups faced problems finding suitable dates to schedule the interviews with the community partners. 
This finding is aligned with the findings of Spronken-Smith (2005), who pointed out that in PBL course the students may suffer multiple stresses, ranging from intense workload to the problems caused by non-contributing team members.

RT 2: The project-based learning approach improved the learning.

In spite of the difficulties involved, the students reported that working in a group was an enjoyable experience: they learned with each other, they learned to deal with conflicts and to respect different points of view. The students also stated that having well-defined deliverables and milestones helped them to keep focus on the research, reducing procrastination.

This finding is similar with the findings of researchers (Arantes do Amaral \& Hess 2015) who reported that PBL contributed to knowledge gain and sharing and to the development of students' competencies.

RT 3: The community-based research was rich and meaningful experience.

Most students felt that in-depth interviews brought them new insights, life lessons and perspectives. The students also felt that interaction with individuals who devote their lives to helping people in need was a very meaningful experience.

This finding is aligned with the findings of researchers (Arantes do Amaral \& Okazaki, 2016), who reported that PBL projects involving community partners contributed to the improvement of the mental models of the students.

RT4: The course developed the students' research skills.

The students also recognized the importance of the course's hands-on approach. They let us know they enjoyed the experience of developing research step-by-step, phase-byphase. They felt that this course contributed to the development of their research skills, which may in turn contribute in the future for the creation of their undergraduate theses.

This finding is aligned to the findings of researchers (Cutforth, 2006; Arantes do Amaral \& Matsusaki, 2017), who point out that PBL hands-on approach develops skills such as critical thinking, the ability to work in groups effectively, and the capacity to solve realworld problems.

\section{Findings from the focus group interview}

The focus group interviews revealed the following causal relationships:

Table 2

The causal relationships, revealed by the focus group interviews:

\begin{tabular}{lll}
\hline Variable & Is influenced positively by & Is influenced negatively by \\
\hline Students' motivation & Quality of the learning & Short time to learn \\
& environment & Difficulty managing the workload \\
& NGO support & Conflicts with non-cooperative team members \\
& Professor's recognition & Fatigue \\
& Excitement of learning & Lack of research skills \\
\hline Excitement of learning & Task accomplished correctly & Rework \\
& Development of research skills & \\
\hline
\end{tabular}




\begin{tabular}{lll}
$\begin{array}{l}\text { Efforts to develop the } \\
\text { team's activities }\end{array}$ & $\begin{array}{l}\text { Students' motivation } \\
\text { Number of tasks to do }\end{array}$ \\
\hline $\begin{array}{l}\text { Conflicts with non- } \\
\text { participative members }\end{array}$ & $\begin{array}{l}\text { Effort to develop the team's } \\
\text { activities }\end{array}$ & \\
\hline $\begin{array}{l}\text { Tasks accomplished } \\
\text { correctly }\end{array}$ & $\begin{array}{l}\text { Effort to develop the team's } \\
\text { activities } \\
\text { Smart room usage }\end{array}$ & $\begin{array}{l}\text { Lack of project management skills } \\
\text { Lack of research skills }\end{array}$ \\
\hline
\end{tabular}

Table 2 shows the six main variables and nineteen variables that influenced them. It reveals that work in teams may trigger dynamics that foster the learning but may also create dynamics that can bring difficulties to the students.

\section{DISCUSSION}

In this section, we make a systemic analysis of the data collected by merging and connecting the qualitative and quantitative data (Creswell, 2013), revealing the dynamics present in the course.

The quantitative data revealed that the majority of the students $(97.5 \%)$ visited the website, watched the videos $(95.6 \%)$ and read the articles $(82.6 \%)$. More than that, the majority of the students $(86.9 \%)$ felt that the course website facilitated the learning. In addition, the majority of the students $(82.7 \%)$ said that having a real institution to do research on also facilitated the learning. Therefore, we can consider that the numbers of articles read, the number of video-lectures watched, and the interactions with institutions had a positive impact on the development of the students' research skills.

In addition, RT2 and RT4 suggested that the project-based learning approach also has a positive impact in the development of the students' research skills. RT3 also suggested that the students considered the community-based research as a meaningful experience, one that had increased their motivation. The focus group interviews also revealed that as the students developed their research skills, they became excited about learning more, in turn improving motivation (Figure 1, 'Learning motivates' loop).

The focus group interview (Table 2) let us understand that the students' motivation was positively affected by the quality of the learning environment, the NGO commitment to support the students, and the professor's recognition.

This dynamic was also described by other researchers in related context, who note that an enjoyable project-based learning environment may have a positive impact on the students' motivation and learning (Arantes do Amaral et al., 2015). More than that, it is also in accordance with the findings of researchers (Arantes do Amaral \& Matsusaki, 2017) that point that the interactions with institutions help the development of the students' skills.

However, the data also revealed that the lack of research skills, the lack of project management skills, the relatively short length of the course and the schedule conflicts negatively affected the students' motivation. We represented these causal relationships in Figure 1, in the top left corner. On the other hand, focus group interviews also revealed that as the project progressed, the level of conflicts between the collaborative 
and non-collaborative members also increased, affecting the motivation of the students (Figure 1, loop 'Conflicts reduce motivation').

RT1 and the focus group interviews revealed that the lack of project management skills and the lack of research skills led, sometimes, in errors in the accomplishment of tasks. When tasks were executed without following proper procedure or without following social science research standards, the professor demanded the students to correct the problems, leading to the increase in the amount of rework to do, therefore increasing the fatigue and decreasing the students' motivation (figure 1, loop 'Rework demotivates'). On the other hand, when the tasks were accomplished correctly, the students reduced the amount of rework, making the project progress (figure 1, loop 'Reducing the number of tasks to do).

This dynamic is related to the findings of researchers who have studied the impact of the lack of project management skills on projects (Cooper, 1993; Sterman, 2000; Lyneis \& Ford, 2007).

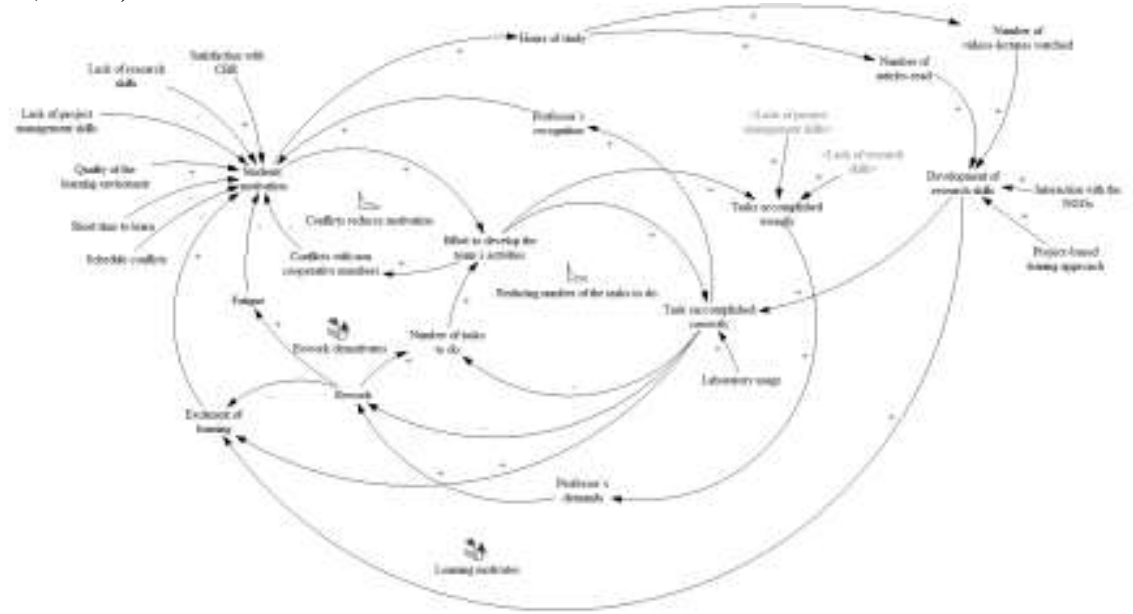

Figure 2

The systemic map of the course

\section{Limitations}

The objective of our course was to provide the students with hands-on experience researching and writing a research article. However, time was limited, first-year students were very young, and none had had previous experience in research methodology or statistics. Some had never read a research journal article before. For these reasons, we defined the research questions ourselves and chose to teach the steps in qualitative rather than quantitative research. To undertake quantitative research would have required instruction in descriptive and inferential research. Moreover, defining the research questions ourselves allowed students the maximum amount of time to undertake all the other research steps: doing the literature review, interviewing, gathering research data, and writing up their findings. 


\section{CONCLUSION}

Reflecting on the experience, we can say that the combination of community-based research and project-based learning provided a rich educational experience. The students learned by doing, with the guidance of the professor and the support of the community partners. The hands-on approach proved valuable in terms of motivation.

The articles created by the students were interesting and insightful: they reflected the students' hard work and commitment. The interviews were accomplished following the recommended procedure and they were a valuable and rich source of information. However, in order for their articles to be publication worthy, improvements still need to be made. Lack of academic maturity was probably a factor here. The articles may be improved in later work that we intend to develop together with the students next year.

What are the disadvantages of this approach?

We feel that although the course was on the whole successful, we should make some changes the next time it is offered. The course would probably have been more useful to students if they had had a previous course in project management. Such a course would have given them experience with working on a team and some knowledge of how to delegate tasks and resolve conflicts. We speculate that with this background, students would probably be able to accomplish the research in a more efficient way. We hope our insights can be helpful to PBL researchers and practitioners.

\section{REFERENCES}

Arantes do Amaral, J. A., Gonçalves, P., \& Hess, A. (2015). Creating a project-based learning environment to improve project management skills of graduate students. Journal of Problem Based Learning in Higher Education, 3(2), 120-130.

Arantes do Amaral, J. A., \& Gonçalves, P. (2016). The use of system thinking concepts in order to assure continuous improvement of project based learning courses. Journal of Problem Based Learning in Higher Education, 3(2).

Arantes do Amaral, J. A., \& Okazaki, E. (2016). University students' support to an NGO that helps children with cancer: Lessons learned in thirteen academic projects. International Journal of Action Research, 12(1), 38-58.

Arantes do Amaral, J. A., \& Matsusaki, C. T. M. (2017). The dynamics of connecting universities, non-governmental organizations and community members by means of academic projects directed at people in need. Educational Action Research, 25(2), 280-299.

Ball, C. T., \& Pelco, L. E. (2006). Teaching research methods to undergraduate psychology students using an active cooperative learning approach. International Journal of Teaching and Learning in Higher Education, 17(2), 147-154.

Bender, W. N. (2012). Project-based learning: Differentiating instruction for the 21st century. Thousand Oaks: Corwin Press.

Chapdelaine, A., \& Chapman, B. L. (1999). Using community-based research projects to teach research methods. Teaching of Psychology, 26(2), 101-105. 
Cooper, K. G. (1993). The rework cycle: How it really works and reworks. PM network, 25-28.

Creswell, J. W. (2013). Research design: Qualitative, quantitative, and mixed methods approaches. Los Angeles: Sage publications.

Gijselaers, W. H. (1996). Connecting problem- based practices with educational theory. New Directions for Teaching and Learning, 1996(68), 13-21.

Larmer, J., \& Mergendoller, J. R. (2010). Seven essentials for project-based learning. Educational Leadership, 68(1), 34-37.

Lyneis, J. M., \& Ford, D. N. (2007). System dynamics applied to project management: a survey, assessment, and directions for future research. System Dynamics Review, 23(2- 3), 157-189.

Longmore, M. A., Dunn, D., \& Jarboe, G. R. (1996). Learning by doing: Group projects in research methods classes. Teaching Sociology, 24(1), 84-91.

Markham, T. (2003). Project based learning handbook: A guide to standards-focused project based learning for middle and high school teachers. Oakland: Buck Institute for Education.

McBurney, D. H. (1995). The problem method of teaching research methods. Teaching of Psychology, 22(1), 36-38.

McConnell, W., \& Marton, J. P. (2011). Introducing students to social science research. Transformative Dialogues: Teaching \& Learning Journal, 5(1), 1-9.

Savery, J. R. (2006). Overview of problem-based learning: Definitions and distinctions. Interdisciplinary Journal of Problem-based Learning, 1(1), 9-20.

Spronken-Smith, R. (2005). Implementing a problem-based learning approach for teaching research methods in geography. Journal of Geography in Higher Education, 29(2), 203-221.

Sterman, J. D. (2000). Business dynamics: systems thinking and modeling for a complex world. Boston: Irwin/McGraw-Hill.

Stocking, V. B., \& Cutforth, N. (2006). Managing the challenges of teaching community-based research courses: Insights from two instructors. Michigan Journal of Community Service Learning, 13(1), 56-65.

Stoecker, R. (2003). Community-based research: From practice to theory and back again. Michigan Journal of Community Service Learning, 9, 35-46.

Winn, S. (1995). Learning by doing: Teaching research methods through student participation in a commissioned research project. Studies in Higher Education, 20(2), 203-214.

Yin, R. K. (2015). Qualitative research from start to finish. New York: Guilford Publications. 


\section{APPENDIX ONE}

1.Have you visited the course website?

$\square$ Yes, several times $\square$ Yes, few times $\square$ No, never

2. Have you watched the video-lectures available at the course website?

$\square$ Yes, all $\square$ Yes, some $\square$ No, none

3. Have you read the articles available at the course website?

$\square$ Yes, all $\square$ Yes, some $\square$ No, none

4. Regarding to the following statement: 'The course website facilitated my learning'

$\square$ I totally agree $\square$ I partially agree $\square$ I am neutral $\square$ I partially disagree $\square$ I totally disagree

4. Regarding to the following statement: 'Having a real institution to do the research facilitated my learning'

$\square$ I totally agree $\square$ I partially agree $\square$ I am neutral $\square$ I partially disagree $\square$ I totally disagree

\section{APPENDIX TWO}

1.Please tell us about your experience of working in groups in order to create a research article.

2.Please tell us about the difficulties you faced in order to create the article.

3.Please tell us about your experience of elaborating and accomplishing the interviews.

4.Please tell us about your experience of contributing to the creation of 'Literature Review' section of the article.

5.Please tell us about your experience of contributing to the creation of 'Discussion Section' of the article.

6.Please tell us about your experience of contributing to the selection of a journal to send your article.

7.Please tell us about your experience of contributing to the selection of searching articles in academic journals databases.

8. Please tell us if about your experience of working the laboratory to do your research.

9. What were the positive and negative aspects of the course?

10. What else would you like to report? 